\title{
Power Flow Analysis for Four Buses System by NR Method
}

\author{
Wint Yu Yu Zaw \\ Department of Electrical Power Engineering, West Yangon Technological University, Yangon, Myanmar
}

\begin{abstract}
How to cite this paper: Wint Yu Yu Zaw "Power Flow Analysis for Four Buses System by NR Method" Published in International Journal of Trend in Scientific Research and Development (ijtsrd), ISSN: 24566470, Volume-3 | Issue-3, April 2019, pp.1508-1511, URL: https://www.ijtsrd.c om/papers/ijtsrd23 472.pdf

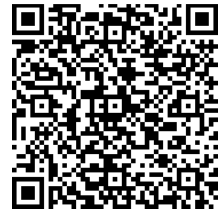

IITSRD23472

Copyright (C) 2019 by author(s) and International Journal of Trend in Scientific Research and Development Journal. This is an Open Access article distributed under the terms of the Creative Commons

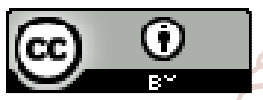
Attribution License (CC BY 4.0) (http://creativecommons.org/licenses/ by/4.0)
\end{abstract}

\section{INTRODUCTION}

The power flow analysis (also known as the load flow problem) is a very important and fundamental tool involving numerical analysis applied to a power system. The analysis is also employed during power system design procedures, planning expansion and development of control strategies. The purpose of any load flow analysis is to compute precise steady-state voltages and voltage angles of all buses in the network, for specified load, generator real power and voltage conditions. Once this information is known, the real and reactive power flows into every line and transformer, as well as generator reactive power output can be analytically determined. Due to the nonlinear nature of this problem, numerical methods are employed to obtain a solution that is within an acceptable tolerance. A power flow analysis for a system operating under actual or projected normal operation conditions (base case) give the results which constitute a benchmark for comparison of changes in the network flows and voltages under abnormal conditions. It is helpful in determining the best location as well as

optimal capacity of proposed generating station, substation and new lines. Power flow analysis is an efficient mean that uses numerical analysis technique for developing a power system. To carry out these analyses, iterative techniques are used due to existence of no known analytical method to solve the problem.

\section{Classification OF BuS}

A bus is a node at which one or many lines, one or various loads and generators are connected. In a power system each node or bus is associated with 4 quantities, such as magnitude of voltage, phase angle of voltage, active or real power and reactive power. In load flow problem two out of these 4 quantities are specified and remaining 2 are required to be determined through the solution of equation. However in power flow analysis, they are classified into three types based on their known as

1. Slack Bus or Swing Bus

2. Generator Bus or Voltage Controlled Bus

3. Load Bus

TABLE I VARIABLES IN POWER FLOW ANALYSIS

\begin{tabular}{|c|c|c|c|}
\hline $\begin{array}{c}\text { Sr. } \\
\text { No. }\end{array}$ & $\begin{array}{c}\text { Type of Bus } \\
\text { (Known) }\end{array}$ & $\begin{array}{c}\text { Variable } \\
\text { (Unknown) }\end{array}$ \\
\hline 1 & Slack or Swing Bus & l V l, ? & P, Q \\
\hline 2 & Load Bus & P, Q & l V l, ? \\
\hline 3 & Voltage Controlled Bus & P, l V l & Q, ? \\
\hline
\end{tabular}

\section{PROBLEM FORMULATION}

A. Power Flow Model Based Newton-Raphson Iteration Method

Power flow analysis based on Newton-Raphson method is an iterative method which approximates a set of non-linear simultaneous equations to a set of simultaneous linear equations using Taylor's series expansion while limiting the term to first order approximation. The Newton-Rsphson method has quadrature convergence characteristics and therefore has less iteration. The Newton Raphson load flow method calculation is shown below. The injected current in term of admittance matrix, 
International Journal of Trend in Scientific Research and Development (IJTSRD) @ www.ijtsrd.com eISSN: 2456-6470

$$
\begin{aligned}
& \mathrm{I}_{\mathrm{i}}=\Sigma_{\mathrm{i}=\mathrm{I}}^{\mathrm{n}}\left|\mathrm{Y}_{\mathrm{i}}\right|\left|\mathrm{V}_{\mathrm{i}}\right| \\
& P_{i}=\sum_{i=1}^{n}\left|V_{1}\right|\left|V_{1}\right|\left|Y_{1}\right| \cos \theta\left(\theta_{1}-\delta_{1}+\delta_{j}\right) \\
& Q_{i}=\Sigma_{j=1}\left|V_{1}\right|\left|V_{j}\right|\left|Y_{j j}\right| \sin \left(A_{1 j}-B_{1}+B_{j}\right)
\end{aligned}
$$

Jacobian Matrix is

$$
\begin{aligned}
& J=\left[\begin{array}{cc}
\frac{\partial \Delta P}{\partial D} & \frac{\partial \Delta P}{\partial|v|} \\
\frac{\partial \Delta Q}{\partial \sigma} & \frac{\partial \Delta Q}{\partial|v|}
\end{array}\right] \\
& {\left[\begin{array}{c}
\Delta \delta \\
\Delta|V|
\end{array}\right]=J^{-1}\left[\begin{array}{c}
\Delta \mathrm{P} \\
\Delta \mathrm{O}
\end{array}\right]}
\end{aligned}
$$

The new voltage magnitude and phase angle,

$$
\begin{aligned}
& \left|V_{i}^{(k+1)}\right|=\left|v_{i}^{(k)}\right|+\Delta\left|V_{i}^{(k)}\right| \\
& =\delta_{\mathrm{i}}^{(k)} \delta_{\mathrm{i}}^{(k)}
\end{aligned}
$$

The line flow and line losses,

$$
\begin{aligned}
& s_{\mathrm{ij}}=P_{\mathrm{ij}}+u_{\mathrm{ij}} \\
& s_{\mathrm{i}}=p_{\mathrm{j}}+\mathrm{Q}_{\mathrm{j}} \\
& s_{\mathrm{L}}=s_{\mathrm{ij}}+s_{\mathrm{ji}}
\end{aligned}
$$

\section{B. Flow Chart For Newton-Raphson Power Flow Solution}

In context to various steps involved in carrying out load flow analysis with Newton Raphson method, following flow chart has been designed:

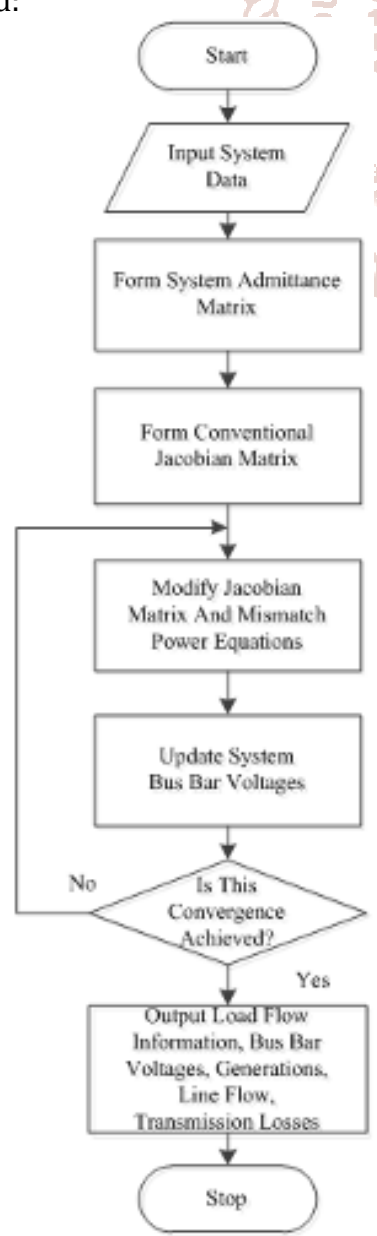

\section{c. Reactive Power Compensation}

Reactive power compensation played benefiting roles in power system such as improving steady-state and dynamic stability, improving voltage profiles of the system and reduction of network loss if correctly placed. Injecting reactive power correctly into the system reduces transmission losses, improves voltage profile of the system and as well decreases line loading. Reactive power can be injected at the specified buses via shunt capacitor to reduce transmission loss, increase system voltage profile and reduce cost of generation.

\section{CASE STUDY}

For the analysis of power flow problems, a sample transmission system is applied. To analyze the transmission line flow and line losses, the application of Shunt Compensator is executed at Lawpita-Taungoo-KamarnatHlawga line which is the longest transmission line in Myanmar. The system block diagram of this line is shown in Figure 2. For this system, the load flow equations are modified correspondingly at four buses. The load flow solution for the modified network is obtained by using Newton-Raphson Method.

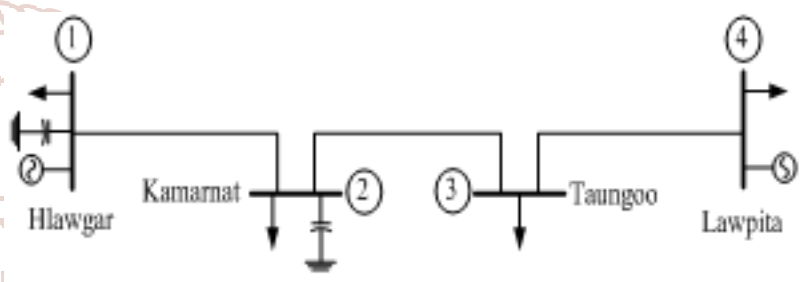

Figure 2.Sample Transmission System

TABLE II DATA OF BUS IN THE SYSTEM

\begin{tabular}{|c|c|c|c|c|c|}
\hline \multirow{2}{*}{ Bus No. } & Assumed Bus & \multicolumn{2}{c|}{ Generation } & \multicolumn{2}{c|}{ Load } \\
\cline { 3 - 6 } & Voltage & MW & Mvar & MW & Mvar \\
\hline 1 & $1.0+\mathrm{j} 0.0$ & 0 & 0 & 80 & 60 \\
\hline 2 & $1.0+\mathrm{j} 0.0$ & 0 & 0 & 64 & 48 \\
\hline 3 & $1.0+\mathrm{j} 0.0$ & 0 & 0 & 64 & 48 \\
\hline 4 & $1.04+\mathrm{j} 0.0$ & 190 & 47.6 & 32 & 24 \\
\hline
\end{tabular}

TABLE III TRANSMISSION LINE PARAMETERS

\begin{tabular}{|c|c|c|c|c|}
\hline $\begin{array}{c}\text { Sr. } \\
\text { No. }\end{array}$ & $\begin{array}{c}\text { Name of } \\
\text { "FROM" } \\
\text { System }\end{array}$ & $\begin{array}{c}\text { Name of } \\
\text { "TO" } \\
\text { System }\end{array}$ & $\begin{array}{c}\text { FROM } \rightarrow \\
\text { TO } \\
\text { Loss Factor } \\
\{\text { R(p.u) }\}\end{array}$ & $\begin{array}{c}\text { FROM } \rightarrow \\
\text { TO } \\
\text { Reactance } \\
\{\mathbf{X}(\mathbf{p u})\}\end{array}$ \\
\hline 1 & Lawpita & Taungoo & 0.052519 & 0.13893 \\
\hline 2 & Taungoo & Kamarnat & 0.004893 & 0.02698 \\
\hline 3 & Kamarnat & Hlawga & 0.005743 & 0.03167 \\
\hline
\end{tabular}

\section{RESULTS}

In this paper, the 4 bus system is analyzed by using Newton Raphson method. The main work of this paper is to develop a MATLAB program to calculate voltages, active and reactive power and losses at each bus for 4 bus systems.

TABLE III RESULTS OF VOLTAGE MAGNITUDE AND ANGLE

\begin{tabular}{|c|c|c|}
\hline \multirow{2}{*}{ Bus No. } & \multicolumn{2}{|c|}{ Bus Voltage } \\
\cline { 2 - 3 } & Magnitude (p.u) & Angle (degree) \\
\hline 1 & 1 & 0 \\
\hline 2 & 0.965 & 0.696 \\
\hline 3 & 0.952 & 2.249 \\
\hline 4 & 1.04 & 14.373 \\
\hline
\end{tabular}

Figure 1.Flow Chart for Newton Raphson Method 
International Journal of Trend in Scientific Research and Development (IJTSRD) @ www.ijtsrd.com eISSN: 2456-6470

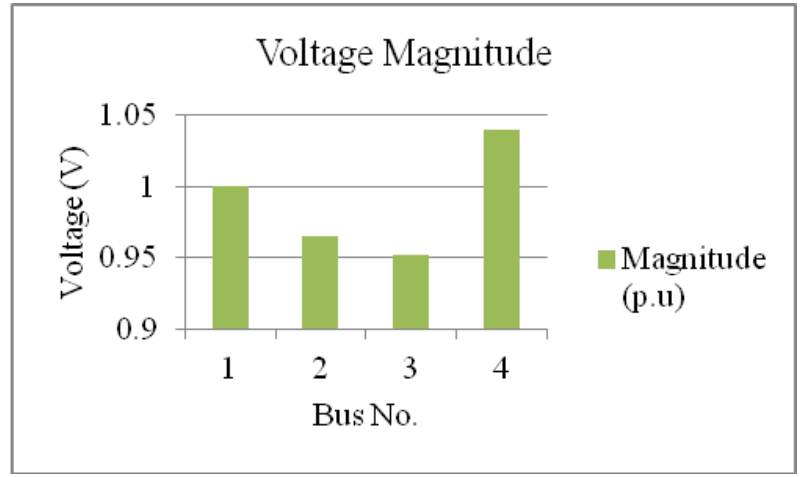

Figure 3.Voltage Magnitude versus Buses

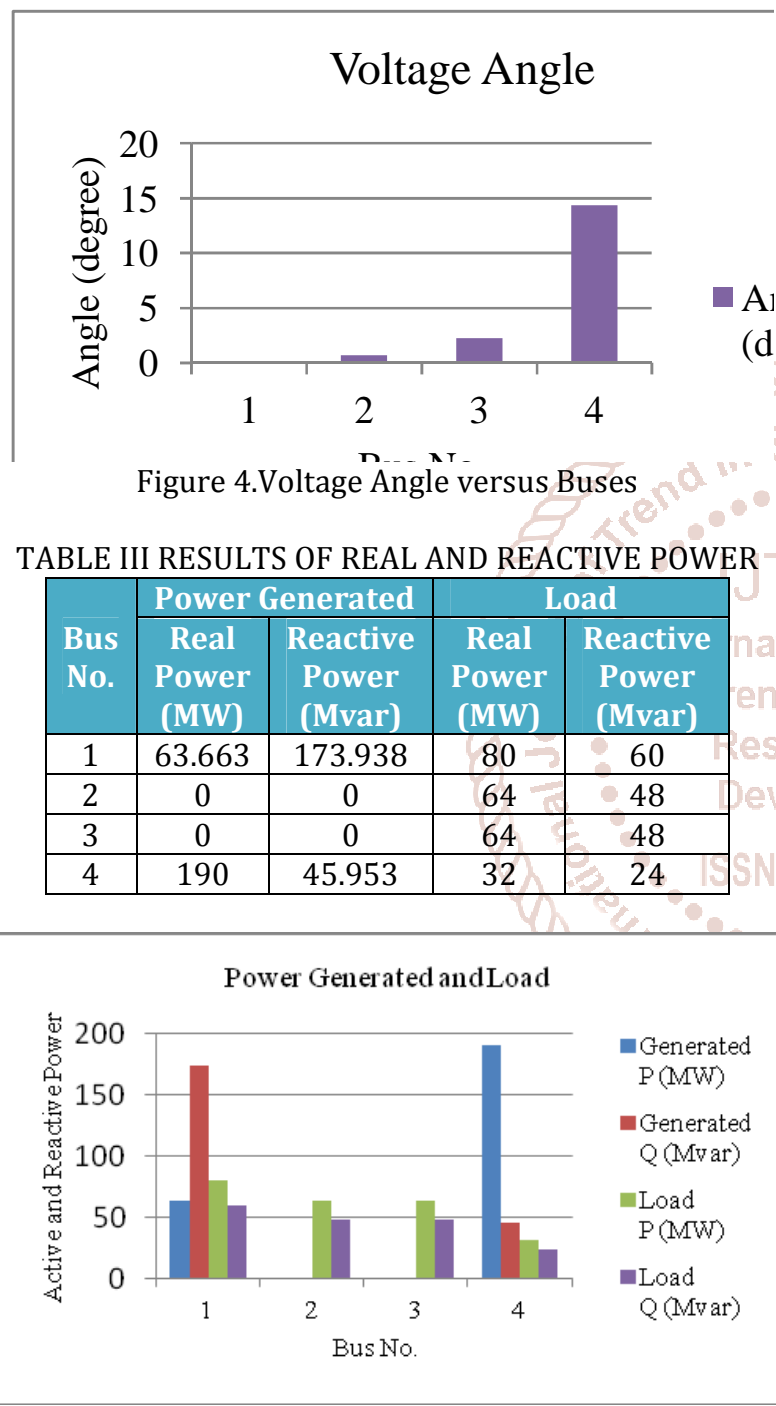

Figure 5.Power Generated and Load

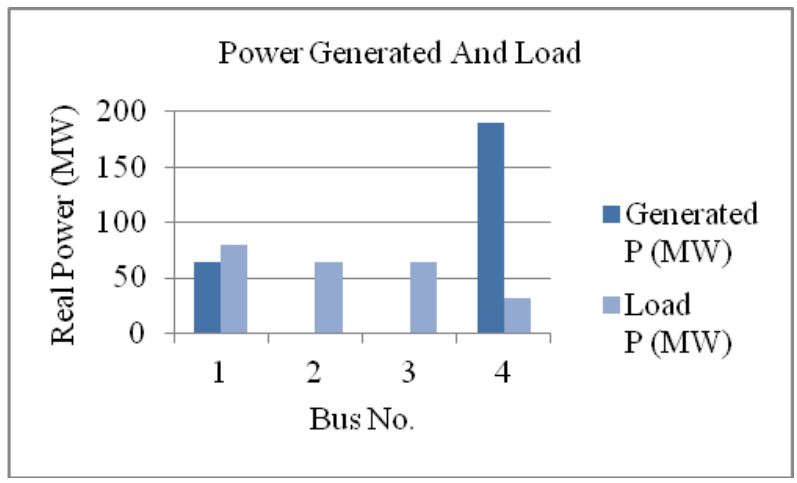

Figure 6.Real Power Generated and Load

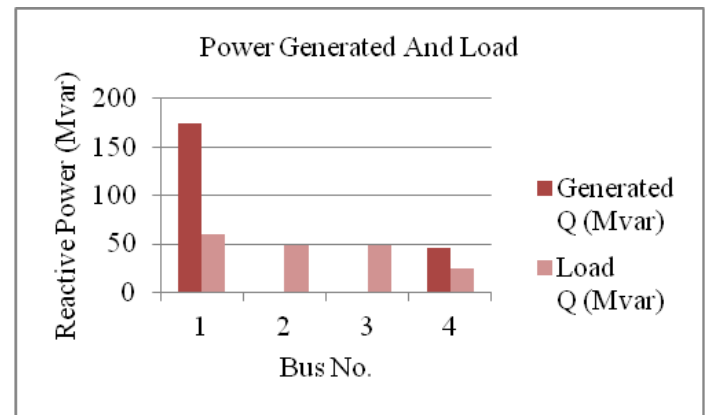

Figure 7.Reactive Power Generated and Load TABLE III LINE FLOW AND LINE LOSS FOR REAL POWER

\begin{tabular}{|c|c|c|c|}
\hline From Bus & To Bus & $\begin{array}{c}\text { Line Flow } \\
\text { (MW) }\end{array}$ & $\begin{array}{c}\text { Line Loss } \\
\text { (MW) }\end{array}$ \\
\hline 1 & 2 & -16.337 & \multirow{2}{*}{0.761} \\
\hline 2 & 1 & 17.098 & \\
\hline 2 & 3 & -81.098 & \multirow{2}{*}{0.546} \\
\hline 3 & 2 & 81.644 & \\
\hline 3 & 4 & -145.644 & \multirow{2}{*}{12.356} \\
\hline 4 & 3 & 158 & \multirow{2}{|c|}{ |otal Loss } \\
\hline
\end{tabular}

TABLE III LINE FLOW AND LINE LOSS FOR REACTIVE POWER

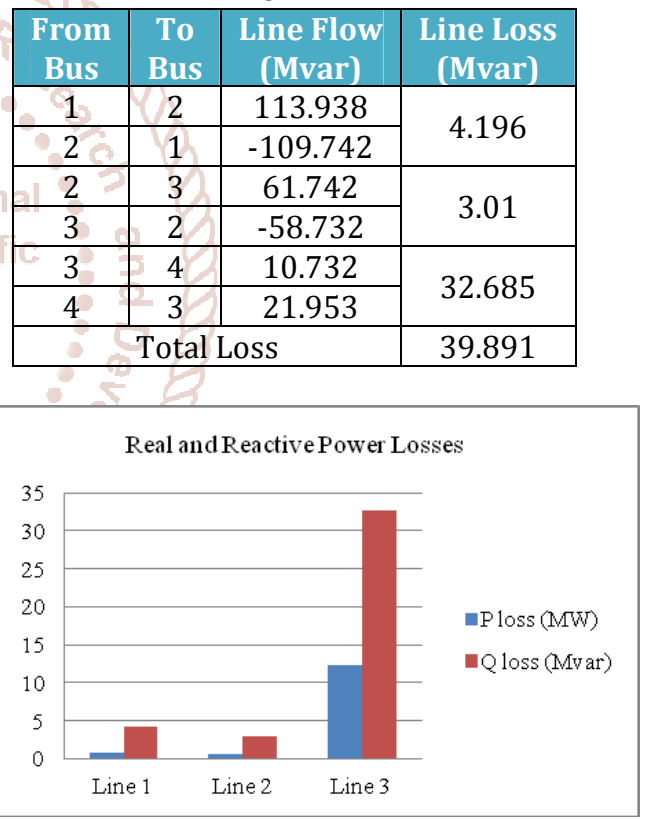

Figure 8.Real and Reactive Power Line Losses

According to TABLE III and IV, the power losses can be observed in Line 1, 2 and 3. Figure 8 shows the line loss at line 1, 2 and 3. Among these, loss at line 3 is more compared to others. Here it can be analyzed that by the use of shunt compensator loss can be minimized in a better way when it will install at the optimal location of the four bus system. In some cases loss is more but generation is also more. Shunt compensation via optimal capacitor placement for the real and reactive power losses reduction and improvement in system voltage profile. If the minimum value of 5 Mvar, Shunt Compensator is set at bus 3, the system power losses are $13.556 \mathrm{MW}$ and $39399 \mathrm{Mvar}$. If the maximum value of 80 Mvar, Shunt Compensator is set at bus 3, the total power losses are $12.645 \mathrm{MW}$ and 34.943 Mvar. From the comparison results, the system performs better when various sizes of Shunt Compensators are connected to a bus 3 as shown in figures 9 and 10 . 


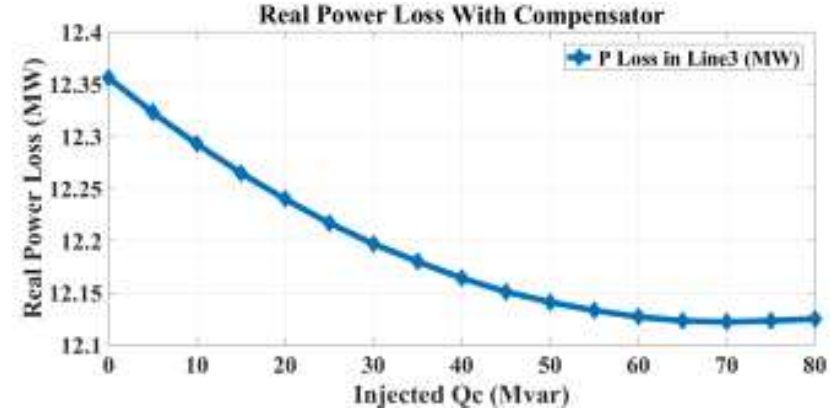

Figure 9.Real Power Losses at Line3

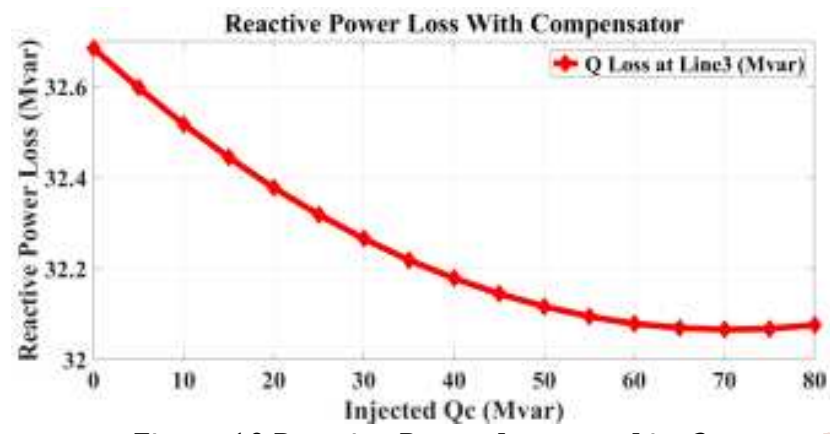

Figure 10.Reactive Power Losses at Line3

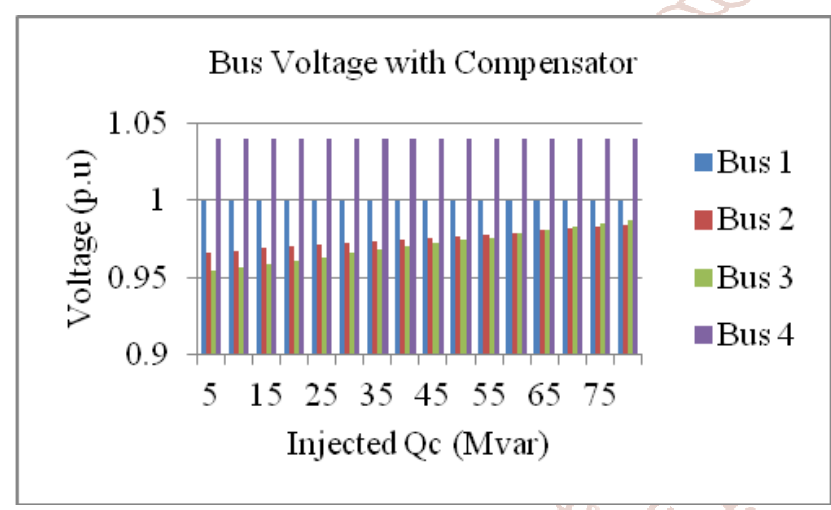

Figure 11.Bus Voltage with Compensator

Figure 11 it can be seen that the variation of voltage magnitude at different buses according to the compensation of various sizes of shunt compensator. It determines the voltage of the buses. The voltage level at the certain buses must be kept within the closed tolerances. It is helpful in determining the best location as well as optimal capacity of proposed generating station, substation and new lines.

\section{CONCLUSIONS}

The power flow analysis for the four bus electrical system has been conducted by using MATLAB program. Here firstly the analysis was done for a normal uncompensated system and its load flow study was investigated in terms of voltage magnitude at all four buses, overall power generation and overall power losses. It was found that by the compensation of shunt capacitor in to the four buses system the voltage stability enhances in terms of magnitude and angle variation and here it is found to be at bus 3. Similarly overall losses (real \& reactive power) also reduced and can be analyzed by means of loss minimization. The study reveals that the injected Mvar brings about reduction in the total cost of generation, the total system losses and a significant improvement in the system voltage profile. Therefore power flow analysis is very important in planning stages of new networks or addition to existing ones like adding new generator sites, meeting increase load demand and locating new transmission sites.

\section{REFERENCES}

[1] G.W.Stagg and A. Abiad. "Computer Methods in Power System Analysis”. McGraw-Hill, New York. $1^{\text {th }}$ edition.

[2] Power System Analysis, Hadi Saadat, McGraw-Hill, International Editions 1999. Boston Burr Ridge, IL Dubuque, IA Madison, WI New York San Francisco St.

[3] Power Flow Study, http://en.wikipedia.org/wiki/Powerflowstudy\# Loadflow.

[4] Stevenson Jr.W.D. "Element of power system analysis".MCGraw-Hill, 4th edition, 2011.

[5] Ganiyu Adedayo Ajenikoko ${ }^{1}$, Olakunle, Elijah Olabode. "Optimal Power Flow with Reactive Power Compensation for Cost And Loss Minimization On Nigerian Power Grid System". Indonesian Journal of Electrical Engineering and Informatics (IJEEI) Vol. 5, No. 3, September 2017, pp. 236 247

[6] uile A.E. and Paterson W.D., "Electrical Power Systems". Vol.2. Pergamon Press, $2^{\text {nd }}$ edition, 2011. 